\title{
Situated Rationality: For a Microscopic Analysis of Scientific Work
}

\section{Ortega Caro C*}

Universidad Arturo Prat, Chile

*Corresponding author: Cristian Ortega Caro, Universidad Arturo Prat, Iquique, Chile, Email: cristiano26x@gmail.com

\section{Conceptual Paper}

Volume 1 Issue 1

Received Date: August 03, 2018

Published Date: September 04, 2018

DOI: $10.23880 /$ phij- 16000104

\begin{abstract}
In what follows, presents a proposal that discussed the production of scientific knowledge from a microscopic perspective, since the classical epistemology (as critical rationalism or Scientific Research Programs), sociology rules of the Science (such as the proposal of Merton) and the Scientometrics fail to express the intersubjective meaning that acquired internal components (logical and methodological) of scientific work. This proposes the concept of "located rationality" in both mechanisms that directs the creation of knowledge, the decisions that this implies, the material location of scientists and the contextual use of the methodological components of the research scientific.
\end{abstract}

Keywords: Located rationality; Epistemology; Production of knowledge; Scientific decisions

\section{Introduction}

From comprehensive sociologies, there is consensus that statistics - if well useful for an macro-structural image of reality - does not see details and processes involved in the generation and development of a phenomenon; for this case, the process of "production of scientific knowledge": i.e., the generation of ideas, theories, concepts and formulas that together help to have a vision of reality; a part of it, a phenomenon or a problem.

However that said, "Scientific production" refers to the quantification of products emanating from the research work, such as the number of publications, patents, universities or disciplines. This underlies an economistic look precisely targeting the production and exchange of goods and services; in this case of "goods and scientific services".

On the other hand, since the conventional epistemology nor is there a conceptual or theoretical systematization on the notion of "knowledge production": for example, the concepts of "context of discovery" and "context of justification" (Reichenbach); or "the community" (Kuhn); and "the traditions" (Laudan), only the ideas of scientific change and progress are limited, but they fail to express the problem of scientific production. It was not until the emergence of Solla Price (Price, D. 1976) analyses and of the Bibliometrics that the concept of "production" entered the debate in the analysis of science and technology [1].

In response to the above, the objective of this article is to situate the process of "scientific production" as a fundamental part of the socio-historical fabric from which is articulated. This not only implies causal in multi-level relationships - as Mannheim postulated it in 1930 [2] or the strong program [3]- but that also implies thinking about a microscopic space where associations and interactions that occur the scientists carried out to generate (also to rebut) an idea, a fact or a theory. Accordingly, what follows, presents a reflection on the space spot where they occur the technical decisions of the production of scientific knowledge. 


\section{Epistemology of Historical Determinism}

The development of scientific knowledge -regardless if it is progress or change -, as well as the "theoretical production" have been dimensions on which has turned the conventional epistemological discussion; on the one hand, the prospect meta-theoretical that interpret the scientistic Protocol from sequential prerogatives, and the validity of the knowledge as a phenomenon of internal criticism. On the other hand, a socio-historical perspective that reflects the phenomenon of science as a result of economic, political or social factors. The first argument, which is useful to express the logical-structural relations of knowledge, is limited in the socio-historical discussion: Merton, Kuhn, Feyerabend, the school of Edinburgh and ethnography in laboratories are critical witnesses of the difficulties of purists rational models and, therefore, of the need for a sociological, historical and political criticism. However, the second argument fails to systematize and seems not to understand the conceptual richness of the technical elements of the scientific work.

However, this does not waste time in discussions on which perspective is more important than the other. What is important is to reflect on how the possibilities and limits of the theoretical production are, on the one hand, historically situated, but at the same time, suspended in a range method-logic which gives a number of options to those who they are in a process of knowledge production. The conjunction of these two poles generates the emergence of a hermeneutics able to locate the theoretical production process. This should take into account, to) that internist science space constitutes a relevant dimension to explain how emerging knowledge production: development, reverse and cognitive stagnation under the logical factors and methodological research; (b) However, the internist science is harmless if you exclude the horizon sociohistorical emerges where the theoretical production; (c) the problem here can elucidate a historical-phenomenological approach that it interpreted the scientific output from the process of "technical decision" that researchers make.

This implies that scientific rationality is made up of three levels:

One macro referred to how scientific reason is installed in a historical continuum that unfolds from the knowledge of the first modernity theory (i.e., from Descartes to Kant) to epistemological reflection at the beginning of the 20th century. Other meso referred to the processes of institutionalization of the reason; i.e., the emergence of research in specialization centers. And one micro referred to actions and individual interactions involved in the

\section{Philosophy International Journal}

specific processes of scientific investigation, referred to the possibilities and limits of maneuverability that scientists ${ }^{[1]}$ in a very technical range of methodological choices/decisions.

In turn, this implies, first, crossing the threshold positivist concept of 'production'; that have been linked to the quantification of a number of aspects that entails the scientific; work on the approach of social science studies and second, overcome the conventional epistemological perspective where the focus of the discussion (concerning theoretical change, validity or progress of knowledge) has been limited by methodological realism that (although it's interesting to the interpretation rational) is insufficient - as well as the pure statistics - to express the scientific process from the actors themselves.

\section{Scientific Rationality in Specific Contexts of Knowledge Production}

The foregoing summons us to a kind of scientific analysis that is not centered in the statistics, or public policy, as in conventional epistemology. On the other hand, the processes of knowledge production are generated by a logic of action, a procedure and assessment; It refers to the location, not only in the global mapping of the science, but the location of the research practice and how in this space to materialize scientific rationality [4].

It means to propose dimensions and levels of a "located rationality", as praxis that connects and interrelates with other scientific actors, research centers and accumulated knowledge (communities disciplinary hand and) traditions on the other epistemic). A perspective of this kind aims to describe and interpret how, from rational variables (for example, objective epistemic paths), variable back (for example, demands on problems of interest $\mathrm{v} / \mathrm{s}$ proposed socio-institutional to solve them) and variables of phenomenological order (for example, assessments/decisions taken in the research process) is generated the contextualization of a rationality that is linked to the process of theoretical production [4]. It has four dimensions by which they could understand the process: i) one referred to the characteristics of the research centers [5]; (ii) that says relationship with partnerships between centers; (iii) another that refers to how you produce in a way not standardized, decisions on the processes of research and iv) a last referred to how from the previous dimensions emerge which could be the creation of knowledge (new or not, is not matter even of) discussion). 
Location and types of research centers (or teams): From our perspective, theoretical production processes are generated from of the topological location of a computer or scientific research center; our perspective is certainly materialistic and prints of identity and dynamism both members of entities as a way are organised disciplinary fields; professions and theoretical assignments [5]; but that the process may be inverse, i.e., that the practices print identity to the entity. Contexts may explain substantial aspects of this or that social practice (in the world of science and elsewhere) as well as practices gives insights into how it operates a specific situation or a social institution [6].

From the theoretical point of view is based on two approaches: neoinstitutionalism applied science [7] and the Ethnography of laboratories [8,9]. The first puts emphasis on regulatory aspects applied to the scientific centers/activity relationship; while the second focuses on one look realistic and context on how occurs onsite scientific practice. In both perspectives fundamental thing is how institutional features of the centers (which socio-political, geographical location, size of the host institution, ranging from issues epistemological and theoretical assignments, to elements of order relations with other centers and access to financing) outline the actions, digressions and decisions made by scientists in a research process.

Ex-situ rationality or the techno-informational dimension of problems-meanings: Scientific problems transcend the physical spaces of an investigation and are installed in a lattice space that is structured, first, from the intellectual universe, i.e., science and unity and tradition of knowledge whose contents are given by the assignment to a discipline; and second, from techno-informational connections scientists adhere to, whose degrees of participation or inclusion are variable depending on the simple sympathy for problematic theoretical or empirical wandering in the intelligentsia Digital, inclusions, alliances and formal cooperation between scientists and research centers. Whatever it is, in both cases is a research praxis techno-connected.

Since a positive heuristic, the questions are how the technological and material component of a research process, is inserted, coupled or uncoupled to the process of knowledge production? How much of this is part of a substantial or philosophical discussion of disciplinary inheritance; or failing, as it responds to the transfer and settlement of concrete scientific problems whose epicenter epistemic (or "basic elements") is, say, in Tokyo with regard to, say, La Paz?
The prospects of "Science in the periphery" [10-13] may well determine how scientific issues and the creation of new knowledge depend on the type of relationships and degrees of connection (by cooperation, alliances or agreements) between research centers. Certainly, the characteristics that make up the scientific rationality, as for example follow certain protocols, methodologies, or ascribe to certain theoretical currents will be influenced by the connections that engage with other centers and/or researchers. Protocols that in fact have more to do with contracts and subcontracts to share a disciplinary community or a tradition to epistemic that discussing, for example, depth, assertiveness, or even beauty of a theory; or whether or in the work carried out is not an approximation to the truth. On the contrary ${ }^{[2]}$, peripheral actors must deal with impositions and subordinations [13], limited access to technologies, non-contextualized disciplinary inheritances and connection problems with the scientific epicenters.

On-site rationality (or the place of scientific decisions): is the space that scientists must decide on what technical elements are useful for their interests. For example, choose with regard to perspectives, theories, procedures and communication of results, etc.; as well as on elements of order non-technical (or social), as the choice of partners, contractual aspects, financing and efforts with non-scientific stakeholders.

The process and social interaction occurring there stabilizes perceptions epistemic among scientists, resulting in a debate on the social order [9], both at a micro level, referred to in the specific space of one order area of study, as a debate on all the social order: decisions that take place in scientific research are, ultimately, decisions that are expressed on a macro level. From Luhmann rationality on-site unfolds from a "double contingency" which refers to identify a situation that may be a way, but at the same time, also of another, i.e., take an alternative course. Thus, the decisions of the actors are contingent [8] every time that they generate not only a sensitivity to the situation (for which there are always more options) but they also manage to stabilize certain social order [14], where order and rationality in situ are the two faces of the same coin.

On the other hand, and from a level micro, rationality in situ is a process consisting of a network of interrelations and linkages between different types of actors $[8,9,15,16]$, which are suspended-trapped in a 'State' that we could call "phenomenological pulsion", that is, the process by which the motivation-need involving the production of knowledge founded a thread of decisions about the path 


\section{Philosophy International Journal}

to follow: the choice, (re) formulation and creation of theories leverages an intuition which, on the one hand, it expands the "accumulated knowledge" (or epistemic tradition), once operates as receptacle which systematizes data and electronic information coming, say, around the globe and, on the other hand, are condensed in order to generate particular solutions to problems of interest, under the kind and nature of research, the available theories (or the taste of scientists), its location in the scientific cartography, networks to wash them attached and the possible results of the investigative process - for more indeterminate than these are. Epistemic digressions and decisions will operate from this point of view, under a very practical logic of rationality and not necessarily under the conditions imposed by a logical Scientifics of macroscopic scale.

\section{Adaptation - transformation - creation of} knowledge: From the actor-network theory of knowledge - production here understood as the process that involves adaptation, transformation and creation of theories - says relationship with a logic that is the research practice (conversations, discussions and decisions with respect to theoretical and methodological aspects) that generates and structure the physical spaces of scientific research and not vice versa. In other words, from a logic of associations are the interrelations between actors, and actors and objects, which explain the emergence both of the process of production of knowledge as the configuration of groups of scientific research and the both, the epistemic definitions and social thematic area and, even, a disciplinary field. The process, stressing, not backward [17].

This has two consequences: one concerning how the technical elements of the conventional epistemological discussion (such as observation; the verification of hypotheses, creation of formulas, follow the protocols; testing, experiments and test, and)prepare records and databases) are understood in their context and phenomenological materiality, every time that the theoretical adaptation and the creation of knowledge requires decision-making sociotechnical that are structured in and from the interaction; and two levels meso, such as the institutionalization of a discipline or the formality of an investigation require this prior decisional process by which describes itself.

From the perspective of the actor, the adaptation, transformation and creation of knowledge could be understandable from a series of threads, such as: i) believe that there is a degree of freedom for creation, invention, genius, also in the empathy and understanding; (ii) assume a beginning of nihilistic criticism, meanwhile, will of power-knowledge channelled through criticism, questioning and nonconformity; ((iii) tenacity and perseverance, on the understanding that the scientific work requires effort and steady work [18]; iv) ability and objectivity; Despite the recognition that here has been sustained on the contextualization of the scientific work; What does not fall into the abyss of relativism; and (v) negotiating capacity, relative to the transactions and agreements taken with other actors, whether or not scientific, but which form directly or not, have a place in the investigative process.

Consequently the adaptation, transformation and knowledge creation, comes to be the space of autonomy (the free use of the method and epistemological traditions) that develops from and for both physical and digital, social interaction and that is where they emerge and structured decisions technical and social; the first much more autonomous and unpredictable from the point of view of the results of an investigation; the second more conditioned by effects of negotiations with other actors, and by the same, more planned and rational according to evaluations ex before between expected knowledge $\mathrm{v} / \mathrm{s}$ material and social conditions of production of knowledge [19-23].

\section{Conclusions}

The production of knowledge emerges depending on a daily network while it is suspended in a series of technical-rational requirements, operating, as social action, as a naturalized phenomenon. Under this point of view the scientific work is not part of a process that seeks to reward, prestige or the Nobel Prize; but it is not a work that seeks the truth, theoretical perfection, or the progress of mankind. Of course that this does not mean that the scientific work not this guided by principles such as the solution of problems or counteract the uncertainties of life. On the other hand, the production of knowledge from microscopic levels of rationality is a process that: Comes into tension with the overall process of Science: beyond the obvious theoretical, conceptual connections and relationships that might exist between scientific equipment; local production is in a contest with respect to its allies. Why this happens?: in principle due to social action, including actions relating to the scientific decisions, cannot set default; There is an ontology that is beyond the assignments that may have methodological rules or protocols. What Knorr-Cetina $[8,9]$ identifies as the "contingencies" that possesses the scientific research, on which from constructivism in laboratories, it is not possible to establish patterns of determinism. 


\section{Philosophy International Journal}

The production of knowledge involves complex processes of autonomy/dependency on the one hand trying to decouple from the scientific epicenters, every time that build spaces of autonomy under a scientific creation that unlocks social mechanisms of determinism, but on the other hand, there are connections technoinformational, formal and not, who directed the technical content of the scientific work.

Paradoxically, all the above refers to the non-place of scientific rationality: space in the framework of the historical evolution of the internist dynamics of science. Non-place that summarizes a locus of autonomy that is the one that generates the constant creation of new, more complete and complex theories.

The foregoing constitutes an expression only understandable from a pop-up "hermeneutic": i.e., an interpretation of the history of science that is built from a locus that is:

a) Highly symbolic (referring to thought and reflection)

b) Which in turn is very material (referring to specific problems of scientific research)

c) Historical (i.e., scientific thinking and empirical problems come together in a "continuum of meaning" that matures over time)

Thus the scientific work is understood from configure interrelationships socio-technical science space generated because of the world-history that is happening to you. It which, obviously, no longer a hypothesis - constitutes the process micro-historical rationality.

\section{References}

1. Kuhn, Thomas (1989) ¿Qué son las revoluciones científicas? Barcelona: Ed. Paídos.

2. Mannheim K (2001) Ideología y Utopía. Introducción a la sociología del conocimiento. México DF: Ed. Fondo de Cultura Económica.

3. Bloor D (1998) Conocimiento e imaginario social. Barcelona: Ed, Gedisa.

4. Wehling, Peter (2006) The situated materiality of science practices: Post constructivism - a new theorical perspective in science studies? Science, Technology and Innovation Studies, STI Studies. Alemania: Universidad de Duisburg-Essen.

5. Hanke C, Gieryn T (2008) Sites of Scientific Practice: The Enduring Importance of Place. In: Hackett E, Amsterdamska 0, Lynch M, Wajcman J (Eds.), The
Handbook of Science and Technology Studies. Massachusetts: The MIT Press.

6. Vaughan, Diane (2009) Analytic Ethnograhy. In: Hedström \& Bearman (Eds.), The Oxford Handbook of Analytical Sociology. Oxford University Press, UK (On line version).

7. Whitley, Richard (2012) La organización intelectual y social de las ciencias. Buenos Aires: Ed. Universidad Nacional de Quilmes.

8. Knorr-Cetina K (1983) The ethnographic study of scientific work: towards a constructivist interpretation of science. KOPS, pp: 115-140.

9. Knorr-Cetina K (2005) La fabricación del conocimiento. Un ensayo sobre el carácter constructivista y contextual de la ciencia. Buenos Aires: Ed. Universidad Nacional de Quilmes.

10. Cueto M (1989) Excelencia científica en la periferia. Lima: GRADE - CONCYTEC.

11. Kreimer P (2000a) Ciencia y periferia: una lectura sociológica. In: La ciencia argentina entre dos siglos. Textos, contextos, instituciones. Buenos Aires: Ed. Manantial.

12. Kreimer P (2000b) Una modernidad periférica? La investigación científica, entre universalismo y el contexto. In: Culturas científicas y saberes locales. Bogotá: Universidad Nacional de Colombia.

13. Kreimer P (2006) ¿Dependientes o Integrados? La ciencia latinoamericana y la nueva división internacional del trabajo. Revista Nómadas 24: 199212.

14. Gonnet JP (2015) Two representations of the social order problem in the sociological theory of Niklas luhmann. Revista Athenea Digital 15(1): 249-269.

15. Latour B, Woolgar S (1995) La vida en el laboratorio. La construcción de los hechos científicos. Madrid: Ed. Alianza.

16. Knorr-Cetina K (1996) Comunidades científicas o arenas transepistémicas de investigación? Una crítica de los modelos cuasi-económicos de la ciencia. Revista REDES 3(7): 1-30.

17. Latour B (2008) Reensamblar lo social. una introducción a la teoría del actor-red. Buenos Aires: Ed. Manantial. 
18. Ander-Egg E (2001) Métodos y técnicas de investigación social I. Acercaq del conocimiento y del pensar científico. Buenos Aires: Ed, Lumen Hvmanitas.

19. Bourdieu Pierre (2008) Los usos sociales de la ciencia. Buenos Aires: Ed, Nueva Visión.

20. Bunge Mario (2004) Emergencia y Convergencia. Novedad cualitativa y unidad del conocimiento. Barcelona: Ed, Gedisa.

21. Lakatos, Imre (2002) Escritos Filosóficos I. La metodología de los programas de investigación científica. Madrid: Ed. Alianza.

22. Latour, Bruno (2001) La esperanza de Pandora. Ensayos sobre la realidad de los estudios de la ciencia. Barcelona: Ed. Gedisa.

23. Merton Robert (2010) Teoría y estructura social. México: Ed. Fondo de Cultura Económica.
[1] Handling in an "extensive" sense referred to technical questions from the point of view of the generation of ideas; and a "narrow" maneuverability referred to technological, economic, political, or ethical barriers that say relationship with the specific problems of research, which will depend, in turn, of the location-connection of the scientists.

[2] "Peripheral" refers to under two connotations: upon one that makes mention of the political and economic status of a country in both aspects of inequality, poverty, underdevelopment and economic dependence. Second, it refers to the physical and virtual location of research centers in the global mapping of the scientific knowledge. The latter is certainly an element whose elucidation is, ultimately, in the subjective network of scientists; they are those who can locate their work in the field. This depends on the meanings on the disciplines to which assigned, used theories, techno-informational connections and participate or not the global conversation of field. For example, in the case of Chile, it is likely that experts in electoral systems located theoretical discussion as gravitational epicenter at continental level; on the other hand, a team of Immunologists work in HIV, is likely to have an opinion, perhaps, less favorable about the location-meaning of his work. 